\title{
Combined Application of Natural Plant Water Extracts and Biochar Improves the Productivity of Bread Wheat
}

\author{
Muhammad Ijaz ${ }^{1}$, Sonia Perveen ${ }^{1}$, Sajid Ali $^{2 *}$, Ahmad Nawaz $^{1}$, Ahmad Sher $^{1}$, Abdul Sattar ${ }^{1,}$ and Sami Ullah ${ }^{1}$ \\ ${ }^{1}$ College of Agriculture, Bahauddin Zakariya University, Bahadur Campus Layyah, Pakistan \\ ${ }^{2}$ Institute of Agricultural Sciences, University of the Punjab, Lahore \\ *Corresponding author email: sajid.iags@pu.edu.pk
}

\begin{abstract}
Bread wheat (Triticum aestivum L.) is staple of Pakistani people. However, its yield at farmer field is low as compared with its genetic potential. Integration of various crop and soil management strategies might be an option to enhance wheat productivity at farmer field. This 2-year experiment was conducted to check the influence of combine application of natural plant water extracts and biochar on the productvity of wheat during the winter season of 2015-16. The experiment consisted of seven treatment viz. (1) control (2) application of biochar $\left(0.18 \mathrm{~kg} \mathrm{pot}^{-1}\right)$ alone, (3) application of sorghum water extract (SWE) alone, (4) application of moringa water extract (MWE) alone, (5) application of biochar + SWE, (6) application of biochar + MWE, (7) application of biochar + SWE+MWE. The results revealed that application of both crop water extracts in combination with biochar improved the growth and grain yield of wheat. Use of MWE in combination with biochar enhanced the grain weight, grain number and grain yield of wheat by 44,14 , and $24 \%$, respectively than the control treatment. In crux, use of MWE in combination with biochar might be a viable option to improve the productvity of bread wheat.
\end{abstract}

Key words: bread wheat, biochar, grain yield, natural water extracts,

\section{Introduction}

Wheat (Triticum aestivum L.) is staple of multiple human communities in the world including Pakistan. In Pakistan, wheat is cultivated on an area of $\sim 9.3$ million hectares with total production of $\sim 25.5$ million tons. Wheat contributes $9.9 \%$ in value added in agriculture and $2.0 \%$ in national GDP. However, the yield of wheat at farmer field is low $\left(2.8 \mathrm{tha}^{-1}\right)$ as compared to its breeding potential [24] in Pakistan and rest of the world.

Numerous factors retard the wheat productvity across globe including Pakistan. Among these, weeds and low soil fertility status (especially very low soil organic matter) are the principle factors responsible for low wheat productvity in the country. Indeed, the climate of most areas of Pakistan is semi-arid subtropical which causes the rapid depletion of soil organic matter due to high prevailing temperature, thus reducing the soil productvity through limiting the nutrient availability to the crops especially wheat.

In this scenario, use of soil amendments possessing the carbon in stable form might be a pragmatic option to improve the soil fertility status of Pakistani soils. Recently, use of biochar has been thought to be a significant carbon sink for agricultural soils owing to the presence of highly stabilized carbon $[1,2,3]$ which may retain in the soil for several decades [3]. Studies have reported that the use of biochar as a soil amendment may improve the efficiency of applied nutrients [4,5,1, 3]. Indeed, biochar application improves soil ash contents thus increasing the soil $\mathrm{pH}$ and cation exchange capacity which improves the nutrient availability $[1,5,6]$. Several studies have reported that biochar application improved the crop growth $[7,8,9,10,11]$ under optimal and sub optimal conditions. 
Today, the phenomenon of use of allelopathy in crop production is also getting the attention of the scientists and crop grower's. Alleloapthy is direct or indirect inhibiting or promoting effect of the one plant/microbe species on the neighboring plants/microbe species through release of certain chemicals known as allelochemicals [12]. These allelochemicals can be artificially extracted from all plant parts and have been reported to improve the crop growth under optimal and sub-optimal conditions when applied at low concentration [13,14]. In recent experiments [14] several folds increase in bread wheat yield has been reported due to the use of artificially prepared natural moringa, sorghum and brassica water extracts, at low concentration, at the farmer field in Punjab, Pakistan.

Indeed, the natural water extracts possesses the phenolics, alkaloids, flavonoids, phenolics, momilactone, terpenoids, brassinosteroids, salicylates, jasmonates, glucosinolates, amino acids, $[15,14,16]$, growth regulators, essential plant minerals $[17,18,19,14,20]$, which improve plant growth when used at low concentration.

Although, the role of biochar [3] and natural plant extracts [21] in improving plant growth under optimal and sub-optimal conditions is well known, no study has been conducted to check the influence of combine application of biochar and natural water extracts for improving bread wheat productvity. Thus, this study was conducted to evaluate the influence of combine application of biochar and natural water extracts on the productvity of bread wheat.

\section{Materials and methods}

\subsection{Site, Soil and Climate}

This study was conducted at Wire House, College of Agriculture, Bahauddin Zakariya University, Bahadur Sub-Campus Layyah, Pakistan during the winter season of 2015-2016. The experiment soil was silty loam having $\mathrm{pH}$ of 7.1.The climate of the study area is semi-arid sub-tropical. Seed of wheat cultivar Galaxy-2013 were used as tested wheat cultivar.

\subsection{Experimental treatments}

The experiment was laid out in completely randomized design (CRD), replicated three times. The experiment consisted of seven treatment viz. (1) control (2) application of biochar alone $(0.18 \mathrm{~kg}$ pot $\left.^{-1}\right)$, (3) application of sorghum water extract alone, (4) application of moringa water extract alone, (5) application of biochar + sorghum water extract, (6) application of biochar + moringa leaf extract, (7) application of biochar + sorghum and moringa water extract.

\subsection{Crop husbandry}

The crop was sown on November 6 and 8, in 2015 and 2016 respectively in earthen pots (each having $5 \mathrm{~kg}$ soils). Firstly, 10 wheat seeds were gently sown in each pot, which were thinned to 4 seeds per pot after uniform emergence. Fertilizer was applied at $0.33 \mathrm{~g} \mathrm{~N}$ and $0.48 \mathrm{~g} \mathrm{P}$ per pot, on the basis of soil analysis report, using diammonium phosphate $(46 \% \mathrm{~N}, 18 \% \mathrm{P})$ and urea $(46 \% \mathrm{~N})$ as sources of $\mathrm{N}$ and $\mathrm{P}$. Whole of the $\mathrm{P} \& \mathrm{~N}$ was applied as starter dose at sowing. Pots were irrigated at each alternate days to maintain crop growth favorable soil moisture.

\subsection{Data recording and statistical analysis}

The spike bearing tillers (productive tillers) were observed from each pot after manual counting and average was worked out. Leaf area was recorded from the standing plants by measuring the leaf length and leaf width. The height of 4 plants was measured from each pot by using the meter 
rod; which was averaged later on. From each pot, four plants were taken and number of spikelets of each spike were counted and their average was worked out. Grains from each spike were threshed and counted separately to workout grains per spike. 1000-grains, separated from straw were counted from each pot and were weighed on an electric balance to record the 1000-grain weight. The chlorophyll content index was recorded by using the chlorophyll meter (CLOI Chlorophyll mete and manufacture by Opti-science campany). The harvested plants were tied up, sundried and the biological yield (total biomass) was estimated by putting the dry plant samples harvested from each pot on an electric balance. After recording data on biological yield, the wheat samples were threshed manually to separate the seeds from starw. The harvest index was estimated as the ration of seed yield to total wheat biomass and was expressed in percentage. The collected data on morphological and yield parameters was analyzed statistically by using "Statistix 8.1" software followed by the separation of treatment means by Least significantly difference test at 5\% [22]. The year effect was non-significant so the data for all parameters was averaged and has been presented as mean of two years.

\section{Results}

This study indicated that the highest productive tillers were recorded when moringa water extract was used in combination with biochar. Sole application of moringa and sorghum water extract in combination with biochar and sole application of biochar without any natural water extract application was equally effective for improvement in leaf area. Application of biochar and natural water extracts alone, or in various combination have no significant effect on the chlorophyll content index and final plant height of wheat. The highest spikelets per spike and grain per spike were recorded with the foliage applied moringa water extract in combination with biochar and that was statistically similar with combined use of moringa and sorghum water extract along with biochar for spikelets per spike, and with the sole application of moringa water extract for grains per spike. Sole application of biochar or its combination with moringa water extract was most effective for improvement in 1000-grain weight. The biological yield was the maximum when biochar was applied in combination with water extract of moringa which was followed by individual moringa water extract application or biochar application in combination with water extracts of sorghum and moringa. The highest grain yield was recorded with the application of moringa water extract along with biochar. Use of biochar and natural water extracts have no significant on harvest index of wheat; nonetheless it was the highest with application of moringa water extract in combination with biochar. Use of moringa water extract in combination with biochar enhanced the leaf area, grains per spike, 1000-grain weight, biological yield and grain yield of wheat by $36,44,14,16$ and $24 \%$, respectively than the control treatment (Table 1). 
Table1: Effect of biochar and natural crop water extracts on productive tiller, leaf area, chlorophyll content index, plant height, spikelets per spike, grains per spike, 1000-grain weight, biological yield, grain yield, and harvest index of bread wheat

\begin{tabular}{|c|c|c|c|c|c|c|c|c|c|c|}
\hline Treatments & PT $\left(\right.$ pot $\left.^{-1}\right)$ & $\mathrm{LA}\left(\mathrm{cm}^{2}\right)$ & $\mathrm{CCI}$ & $\mathrm{PH}(\mathrm{cm})$ & SPS & GPS & TGW (g) & $\begin{array}{l}\text { BY } \\
\text { (g/pot) }\end{array}$ & GY (g/pot) & HI $(\%)$ \\
\hline $\mathrm{T}_{1}$ & $12.0 \mathrm{D}$ & $25.6 \mathrm{~B}$ & 10.8 & 55.4 & $12.6 \mathrm{BC}$ & $22.5 \mathrm{CD}$ & $32.4 \mathrm{BC}$ & $22.4 \mathrm{~B}$ & $10.4 \mathrm{C}$ & 46.4 \\
\hline $\mathrm{T}_{2}$ & $12.8 \mathrm{~B}$ & $31.9 \mathrm{~A}$ & 11.2 & 64.1 & $12.8 \mathrm{BC}$ & $22.8 \mathrm{D}$ & $35.9 \mathrm{~A}$ & $23.0 \mathrm{~B}$ & $11.0 \mathrm{BC}$ & 47.8 \\
\hline $\mathrm{T}_{3}$ & $12.8 \mathrm{~B}$ & $30.7 \mathrm{AB}$ & 10.5 & 54.4 & $12.0 \mathrm{C}$ & 17.8 BCD & $35.0 \mathrm{AB}$ & $21.9 \mathrm{~B}$ & $10.5 \mathrm{C}$ & 47.9 \\
\hline $\mathrm{T}_{4}$ & $12.6 \mathrm{BC}$ & $30.8 \mathrm{AB}$ & 11.0 & 58.5 & $12.8 \mathrm{BC}$ & $27.9 \mathrm{AB}$ & $30.2 \mathrm{C}$ & $21.9 \mathrm{AB}$ & $10.6 \mathrm{C}$ & 48.4 \\
\hline $\mathrm{T}_{5}$ & $12.6 \mathrm{BC}$ & $32.1 \mathrm{~A}$ & 11.8 & 59.9 & $12.9 \mathrm{ABC}$ & $25.2 \mathrm{ABC}$ & $34.6 \mathrm{AB}$ & $24.2 \mathrm{~B}$ & $11.4 \mathrm{~B}$ & 47.1 \\
\hline $\mathrm{T}_{6}$ & $13.4 \mathrm{~A}$ & $34.7 \mathrm{~A}$ & 11.9 & 64.8 & $14.3 \mathrm{~A}$ & $32.4 \mathrm{~A}$ & $36.9 \mathrm{~A}$ & $25.9 \mathrm{~A}$ & $12.9 \mathrm{~A}$ & 49.8 \\
\hline $\mathrm{T}_{7}$ & $12.2 \mathrm{CD}$ & $31.0 \mathrm{AB}$ & 11.0 & 59.8 & $13.6 \mathrm{AB}$ & $26.2 \mathrm{BCD}$ & $34.0 \mathrm{AB}$ & $23.4 \mathrm{AB}$ & $11.0 \mathrm{BC}$ & 47.0 \\
\hline $\operatorname{LSD}(p \leq 0.05)$ & 0.45 & 0.63 & $\mathrm{~ns}$ & ns & 1.46 & 1.5 & 3.07 & 0.89 & 0.76 & $\mathrm{~ns}$ \\
\hline
\end{tabular}

$\mathrm{T}_{1}=$ control (no biochar and natural water extract application); $\mathrm{T}_{2}=$ application of biochar $\left(0.18 \mathrm{~kg}_{\text {pot }}{ }^{-1}\right) ; \mathrm{T}_{3}=$ application of sorghum water extract; $\mathrm{T}_{4}=$ application of moringa water extract; $\mathrm{T}_{5}=$ application of biochar + sorghum water extract; $\mathrm{T}_{6}=$ application of biochar + moringa water extract; $\mathrm{T}_{7}=$ application of biochar + moringa and sorghum water extracts; $\mathrm{PT}=$ productive tiller; $\mathrm{LA}=$ leaf area; $\mathrm{PH}=$ plant height; $\mathrm{CCI}=$ chlorophyll content index; $\mathrm{SPS}=$ spikelets per spike; GPS= grains per spike; TGW=1000-grain weight; $\mathrm{BY}=$ biological yield; $\mathrm{GY}=$ grain yield; $\mathrm{HI}=$ harvest index; $\mathrm{ns}=$ non-significant 


\section{Discussion}

This study indicated that leaf area was improved by the application of natural water extracts and biochar either applied alone or various combinations. Combine application of moringa water extract and biochar was the most effective treatment than the other treatments. Indeed, biochar application has the ability to improve the crop productvity owing to the presence of highly stabilized carbon (Hussain et al. 2017), which improves the availability of applied nutrients [1,3], thus improving the crop performance as was observed in this study. Several studies have reported that biochar application improved the crop growth $[9,10,11]$, under optimal and sub optimal conditions.

On the other hand, application of moringa water extract was most beneficial. Indeed, moringa water extracts consist of growth regulators (e.g. zeatin), phenolics, antioxidants and other multiple nutrients (e.g. calcium, iron and zeatin) [20,16], which may positively influence the crop growth when applied at low concentration. Earlier, Fuglie [17] reported that the leaf extracts of moringa increases the growth of young plants, improves the leaf area and finally the yield, and the same was observed in this study.

Thus, when both the biochar and moringa water extract were applied in combination, their positive influence on wheat growth was enhanced several folds. More leaf area due to combine application of moringa water extract and biochar resulted in the provisions of more leaf surface area to harvest the photosynthetically active radiation which ultimately improved the crop growth which was visible through better final height and more number of productive tillers in this treatment. This improvement in growth parameters lead towards better source to sink relationship and the better grain partitioning which resulted in highest grain weight and grain number. Thus the improved grain yield due to moringa water extract and biochar was due to better growth which improved the grain filling and finally the yield.

Application of sorghum water extract was also beneficial for improvement in crop growth and yield than the control treatment. Indeed, sorghum water extract consist of various phenolic compounds (e.g. vanillic acid, syringic acid, p-coumaric acid, ferulic acid, and p-hydroxybenzoic acid $[23,16]$, which have the ability to improve the crop growth when used at low concentration as was observed in this study.

\section{Conclusions}

Application of biochar and natural water extracts improved the growth and yield of bread wheat than the control treatment. In this regard, combine application of biochar and moringa leaf extract was most beneficial for improvement in growth, yield related parameters and grain yield of bread wheat under agro-climatic conditions of Layyah, Punjab, Pakistan.

\section{References}

1. Glaser, B.; Lehmann, J.; Zech, W. Ameliorating physical and chemical properties of highly weathered soils in the tropics with charcoal-a review. Biol. Fertil. Soils 2000, 35, 219230.

2. Kammann, C.; Linsel, S.; Gößling, J.; Koyro, H.W. Influence of biochar on drought tolerance of Chenopodium quinoa Willd and on soil-plant relations. Plant Soil 2011, 345, 195-210.

3. Hussain, M.; Farooq, M., Nawaz, A.; Al-sadi, A.M.; Solaiman, Z.M.; Alghamdi, S.S.; Ammara, U.; Ok Y.S.; Siddique, K.H.M. Biochar for crop production: potential benefits and risks. J. Soils Sed. 2017, 17, 685-716. 
4. Doydora, S.; Cabrera, M.L.; Das K.C.; Gaskin, J.W.; Simon, L.S.; Miller, W.P. Release of nitrogen and phosphorus from poultry litter amended with acidified biochar. Int. J. Environ. Res. Public Health. 2011, 8, 1491-502.

5. Streubel, J.D.; Collins, H.P.; Garcia-perez, M.; Tarara, J.; Granatstein, D.; Kruger, C.E. Influence of contrasting Biochar types on five soils at increasing rates of application. Soil Sci. Soc. Am. J. 2011, 75, 1402-1413.

6. Unger R.; Killorn, R. Effect of the application of biochar on selected soil chemical properties, corn grain, and biomass yields in Iowa. Comm. Soil Sci. Plant Anal. 2011, 42, 2441-2451.

7. Asai, H.; Samson, B.K.; Stephan, H.M.; Songyikhangsuthor, K.; Homma, K.; Kiyono, Y.; Inoue, Y.; Shiraiwa, T.; Horie, T. Biochar amendment techniques for upland rice production in Northern Laos 1. Soil physical properties, leaf SPAD and grain yield. Field Crops Res. 2009, 111, 81-84.

8. Chan, K.Y.; Van zwieten, L.; Meszaros, I.; Dowie, A.; Joseph, S. Using poultry litter biochars as soil amendments. Aust. J. Soil Res. 2008, 46, 437- 444.

9. Major, J.; Lehmann, J.; Rondon, M.; Goodale, C. Fate of soil-applied black carbon: downward migration, leaching and soil respiration. Glob. Change Biol. 2009, 16, 13661379.

10. Graber, E.R.; Meller-harel, Y.; Kolton, M. Biochar impact on development and productivity of pepper and tomato grown in fertigated soilless media. Plant Soil. 2010, 337, 481-496.

11. Hossain, M.K.; Strezov, V.; Yin Chan, K.; Nelson, P.F. Agronomic properties of wastewater sludge biochar and bioavailability of metals in production of cherry tomato (Lycopersicon esculentum). Chemosphere. 2010, 78, 1167-1171.

12. Weston, L.A.; Alsaadawi, I.S.; Baerson, S.R. Sorghum allelopathy from ecosystem to molecule. J. Chem. Ecol. 2013, 39, 625-637.

13. Anwar, S.; Shah, W.A.; Shafi, M.; Bakht, J.; Khan, M.A. Efficiency of sorgaab (sorgaab) and herbicide for weed control in wheat (Triticum aestivum) crop. Pak. J. Weed Sci. Res. 2003, 9, 161- 170 .

14. Cheema, Z.A.; Farooq, M.; Wahid, A. Allelopathy: Current Trends and Future Applications. Springer: Verlag Berlin Heidelberg, Germany. 2014,

15. Kruse, M.; Strandberg, M.; Strandberg, B. Ecological effects of allelopathic plants-a review, National Environmental Research Institute. NERI, Technical Report No. 315, Silkeborg 2000, p. 66.

16. Jabran, K.; Farooq, M. Implications of potential allelopathic crops in agricultural systems. In: Allelopathy: Current Trends and Future Applications. In: Cheema ZA, Farooq M, Wahid, A. editors. Springer, Verlag Berlin Heidelberg, 2013, Germany, p. 349-385.

17. Fuglie, L.J. The miracle tree: Moringa oleifera: natural nutrition for the tropics. Church World Service, 1999, Dakar 68.

18. Anwar, F.; Latif, S.; Ashraf, M.; Gilani, A.H. Moringa oleifera: A food plant with multiple medicinal uses. Phyt. Res. 2007, 21, 7-25.

19. Basra, S.M.A. Moringa leaf extract: a natural crop growth enhancer. In: Proc. Intl. Seminar on 'Crop Management: Issues and Options', Univ. Agri., Faisalabad, Pakistan, June 1-2, 2011, pp. 21.

20. Hussain, M.; Farooq, M.; Basra, S.M.A.; Lee, D.J. Application of moringa allelopathy in crop sciences. In: Allelopathy: Current Trends and Future Applications. In: Cheema, Z.A; 
Farooq, M.; Wahid, A. editors. Springer, Verlag Berlin Heidelberg, 2013, Germany, p. 469-484.

21. Farooq, M.; Rizwan, M.; Nawaz, A.; Rehman, A.; Ahmad, A. Application of natural plant extracts improves the tolerance against combined terminal heat and drought stresses in bread wheat. J. Agron. Crop Sci. 2017, 203, 528-538

22. Steel, R.G.D.; Torrie, J.H.; Dickey, D.A. Principles and procedures of statistics: a biometrical approach, 3rd Ed. McGraw Hill Book Co. Inc. 1996, pp. 352-358. New York, USA.

23. Cheema, Z.A.; Mushtaq, M.N.; Farooq, M.; Hussain, A.; Din I.U. Purple nutsedge management with allelopathic sorghum. Allelopathy J. 2009, 23, 305- 312.

24. Government of Pakistan. Pakistan Bureau of Statistics. 2016, Islamabad 